\title{
THE EFFECTS OF GAMMA-RAY ON THE MECHANICAL PROPERTIES OF Zr-BASED BULK METALLIC GLASS
}

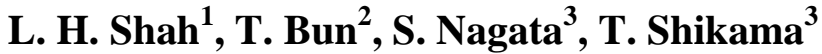 \\ ${ }^{1}$ Faculty of Mechanical Engineering, Universiti Malaysia Pahang, \\ 26300 UMP, Kuantan, Pahang, Malaysia; Phone: +6012-3456789, Fax: +609-87654321 \\ E-mail: luqmanhakim@ump.edu.my \\ ${ }^{2}$ Faculty of Science and Technology, Department of Culture Education, Meijo \\ University, Shiogamaguchi City, Nagoya Prefecture, Japan. \\ E-mail: tsuchiya@imr.tohoku.ac.jp \\ ${ }^{3}$ Institute for Materials Research, Tohoku University, Sendai City, \\ Miyagi Prefecture, Japan. \\ E-mail: nagata@imr.tohoku.ac.jp
}

\begin{abstract}
The effect of gamma-ray irradiation on the mechanical properties of $\mathrm{Zr}_{55} \mathrm{Ni}_{5} \mathrm{Al}_{10} \mathrm{Cu}_{30}$ bulk metallic glass (BMG) was investigated. The samples were irradiated with a gamma-ray dose up to $2090.24 \mathrm{kGy}$ prior to mechanical property investigations. Vickers hardness test, nano-indentation test as well as speed of sound measurements in order to calculate the material's elastic moduli were conducted. An x-ray diffractogram device was also utilized to observe the BMG's devitrification behavior. Results confirm that no significant changes were observed for any of the samples. XRD spectra of irradiated BMGs also show uniform broad peaks, indicating an amorphous structure inside the sample. This result indicates that a gamma-ray irradiation dose of up to $2090.24 \mathrm{kGy}$ does not change the mechanical properties and the microstructure of the material, thus making it a good future structural candidate for gamma-ray rich environments.
\end{abstract}

Keywords: Bulk metallic glass; gamma-ray irradiation; mechanical properties.

\section{INTRODUCTION}

From its introduction in the early nineties, Zr-based bulk metallic glass has attracted much attention due to its unique properties, such as superior strength (up to $2 \mathrm{GPa}$ ), high elastic strain limit $(\sim 2 \%)$, relatively low Young's modulus (50-100 GPa), excellent corrosion resistance and improved wear resistance (Bruck et al, 1994; Gilbert et al, 1997; Inoue, 1995; Johnson, 1999; Liu et al, 2005; Pang et al, 2000; Wang et al, 2000). Due to its thermal stability and excellent mechanical properties, it is no wonder that such material is gaining popularity in various engineering fields, such as in biomedical applications (Liu et al, 2007) and in structural applications in irradiation rich environments (Shah et al, 2011). However, previous investigations conducted by Higashi (2005) reported that gamma-ray irradiation induced a suppression in $\mathrm{Zr}-\mathrm{Ni}$ phase precipitation with a very low dose of $10 \mathrm{kGy}$ during the annealing process of a $\mathrm{Zr}_{55} \mathrm{Ni}_{5} \mathrm{Al}_{10} \mathrm{Cu}_{30} \mathrm{BMG}$ sample [10]. This led to the conclusion that the local atomic structure of the sample was changed by gamma-ray irradiation. Furthermore, previous research conducted by Shah et al (2008) also reported the same finding for higher 
gamma-ray doses, but noted that irradiation did not change the material's electrical properties or its super cooled liquid region, $\Delta \mathrm{T}_{\mathrm{x}}$ (Shah et al, 2011). Coupled with scarce information, it is therefore of great interest to examine the effect that gamma-ray irradiation has on the mechanical properties of Zr-based BMGs. This study conducted several tests to observe any changes in the material's mechanical properties due to various doses of gamma-ray irradiation.

\section{EXPERIMENTS}

A $\mathrm{Zr}$-based BMG with a composition ratio of $\mathrm{Zr}_{55} \mathrm{Ni}_{5} \mathrm{Al}_{10} \mathrm{Cu}_{30}$ was used in this research due to its popularity as a metallic glass system which possesses high thermal stability and a large $\Delta T_{x}$ (Iqbal et al, 2007). The bulk sample was prepared by casting the melt into a copper mold in an argon atmosphere. The bulk sample is then cut into several $5 \times 5 \times 2 \mathrm{~mm}^{3}$ cuboids and $25 \times 2 \times 0.5 \mathrm{~mm}^{3}$ bars for experimentation, using an Isomet Buehler low speed diamond saw. Finally, the cut samples are cleaned with ethanol.

\section{Gamma-ray irradiation process}

The cuboid and bar samples were taken to the Japan Atomic Energy Agency (JAEA) Takasaki Advanced Radiation Research Institute for the gamma irradiation process in a Cobalt 60 irradiation facility, within the energy range of $1.17 \mathrm{MeV}$ and $1.33 \mathrm{MeV}$. The various gamma doses were calculated to be up to $2090.24 \mathrm{kGy}$. The gray dose rate is related to the flux of the gamma ray photons

$$
D=\left(\Phi \times \mu_{a}\right) /\left(\rho \times E_{\gamma}\right)
$$

where $D$ is the gray dose [Gy]

$\Phi$ is the photon fluence [photons $/ \mathrm{cm}^{2}$ ]

$\mu_{a} / \rho$ is the mass absorption coefficient $\left[\mathrm{cm}^{2} / \mathrm{g}\right]$

$E_{\gamma}$ is the energy of incident gamma radiation,

$$
(1.17+1.33) / 2=1.25 \mathrm{MeV}=1.25 \times 10^{6} \times 1.602 \times 10^{-19} \mathrm{~J}=2.0025 \times 10^{-13} \mathrm{~J}
$$

With referrence to the mass absorption coefficient of $\mathrm{Cu}$ (Ishino, 1979) we obtain $\mu_{\mathrm{a}} / \rho=$ $0.0247 \mathrm{~cm}^{2} / \mathrm{g}$. Calculating the highest gamma ray dose of $2090.24 \mathrm{kGy}$ ( $=2090.24 \mathrm{Jg}^{-}$ ${ }^{1}$ ), from Eq. (1) we calculate the gamma irradiation fluence to be

$$
\begin{aligned}
\Phi & =\left(2090.24 \mathrm{Jg}^{-1}\right) \div\left(0.0247 \mathrm{~cm}^{2} \mathrm{~g}^{-1} \times 2.0025 \times 10^{-13} \mathrm{~J}\right) \\
& =\left(2090.24 \mathrm{Jg}^{-1}\right) \div\left(4.9462 \times 10^{-15} \mathrm{Jcm}^{2} \mathrm{~g}^{-1}\right) \\
& =4.23 \times 10^{17} \text { photons } / \mathrm{cm}^{2}
\end{aligned}
$$

The cross-sectional displacement due to Compton scattering, $\sigma_{\mathrm{p}}$, for $\mathrm{Cu}$ (while assuming the displacement energy, $\mathrm{E}_{\mathrm{d}}$, to be $25 \mathrm{eV}$ (Dienes and Vineyard, 1957)) is roughly 0.1 $\times 10^{-24} \mathrm{~cm}^{2}$. Therefore the displacement per atom (dpa), $\mathrm{N}$, for $\mathrm{Cu}$ with a gamma incident energy of $1.25 \mathrm{MeV}$ is

$$
N=\Phi \times \sigma_{p}=4.23 \times 10^{17} \times 0.1 \times 10^{-24}=4.23 \times 10^{-8} \mathrm{dpa}
$$

Thus we can assume that the highest dpa for the gamma-ray irradiated $\mathrm{Zr}_{55} \mathrm{Ni}_{5} \mathrm{Al}_{10} \mathrm{Cu}_{30}$ BMG sample to be of the order of $\sim \times 10^{-8} \mathrm{dpa}$. 


\section{Speed of Sound Measurements}

The speed of sound measurements was conducted using a Karl Deutsch D-56 Wuppertal1 Echometer 1061 with a contact probe and probe gel, and a Tektronix TDS 2012 two-channel storage digital oscilloscope. Two distinctive probes were used for the transverse and longitudinal waves. The spread time of the longitudinal waves, $t_{l}$ and the transverse waves, $t_{t}$ were measured by fixing the speed of sound dial at $0.200 \mathrm{~cm} / \mu \mathrm{s}$.

Obtaining the value of $t_{l}$ and $t_{t}$ from the above experiment, we can calculate the speed of sound for the longitudinal waves of the samples, $v_{l}$, to be

$$
v_{l}=(2 \times l) /\left(1000 \times t_{l}\right) \mathrm{ms}^{-1}
$$

and the speed of sound for the transverse waves, $v_{t}$, is

$$
v_{t}=(2 \times l) /\left(1000 \times t_{t}\right) \mathrm{ms}^{-1}
$$

where $l$ is the sample's thickness. From this result, the elastic moduli, namely shear (G), bulk (K) and Young's (E) modulus, as well as the Poisson's ratio (v) can be calculated by inserting the speed of sound values into the following equations (Kai et al, 2002):

$$
\begin{gathered}
\mathrm{G}=d \times v_{t}^{2}[\mathrm{GPa}] \\
\mathrm{K}=d \times\left\{v_{l}^{2}-(4 / 3) \times v_{t}^{2}\right\}[\mathrm{GPa}] \\
\mathrm{E}=3 d \times v_{t}^{2} \times\left\{v_{l}^{2}-(4 / 3) \times v_{t}^{2}\right\} /\left(v_{l}^{2}-v_{t}^{2}\right)[\mathrm{GPa}] \\
v=\left(v_{l}^{2}-2 v_{t}^{2}\right) /\left(2 v_{l}^{2}-2 v_{t}^{2}\right)[\mathrm{GPa}]
\end{gathered}
$$

where $d$ is the density of the sample.

\section{Hardness Test}

In order to investigate the plastic deformation of the surface of the material due to gamma irradiation, a nanoindentation test and Vickers hardness test were conducted. The device used in this test was the Elionix ENT-1100a UMIS (Ultra-Micro Indentation System) and a Matsuzawa Vickers hardness device, located in Tohoku University's Institute for Materials Research Facility in Ooarai. The x-ray diffraction experiment was conducted at the National Institute for Fusion Science (NIFS) in Nagoya, using an x-ray diffractogram device to observe any changes in the BMG's amorphous structure after the irradiation process.

\section{RESULTS AND DISCUSSION}

The results of the speed of sound measurements are shown below. Figure 1 shows the longitudinal and transverse waves values, whilst Figures 2 and 3 show the calculated values of the elastic moduli, namely the bulk, Young's and shear moduli, and Poisson's ratios for various doses of gamma ray up to $2090.24 \mathrm{kGy}$. All elastic modulus value 
show relatively similar values, and did not present any changes due to gamma irradiation doses up to $2090.24 \mathrm{kGy}$.

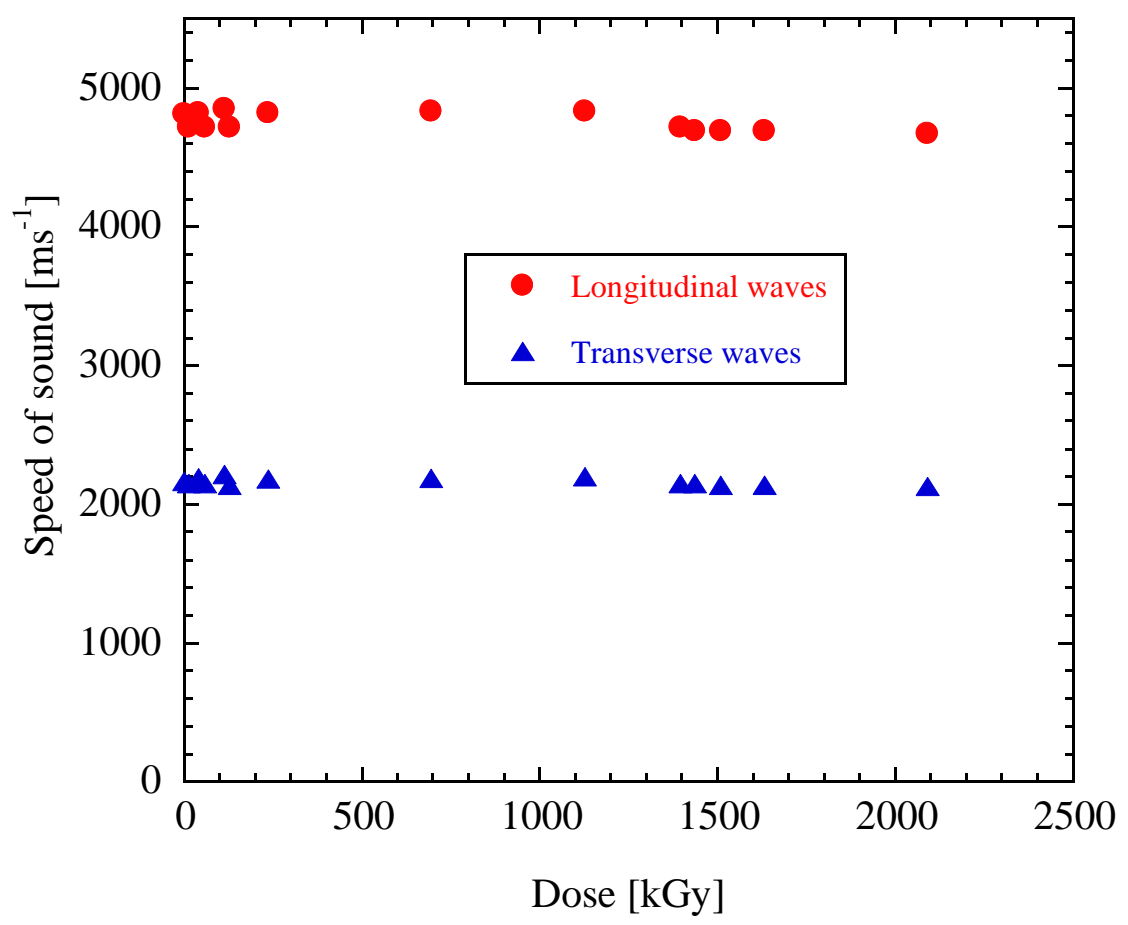

Figure 1. Speed of sound for various doses of gamma-ray up to 2090.24 kGy

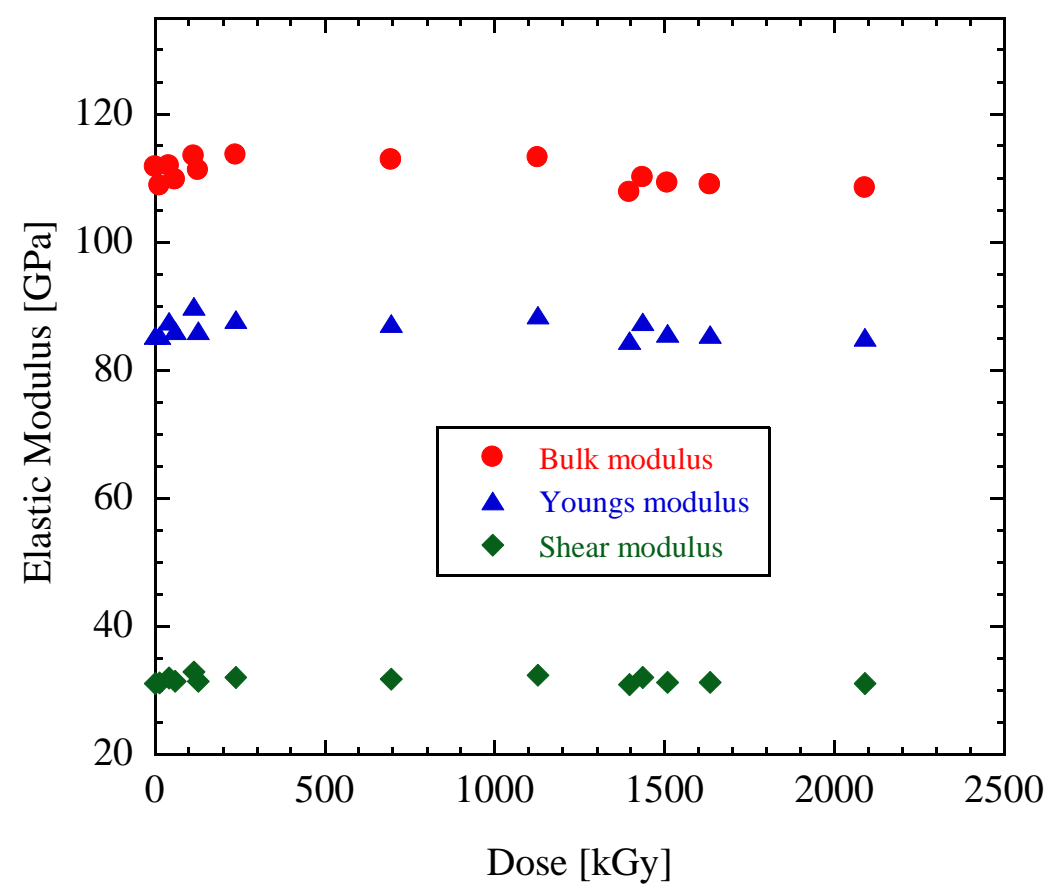

Figure 2. Elastic modulus for various doses of gamma-ray up to $2090.24 \mathrm{kGy}$ 


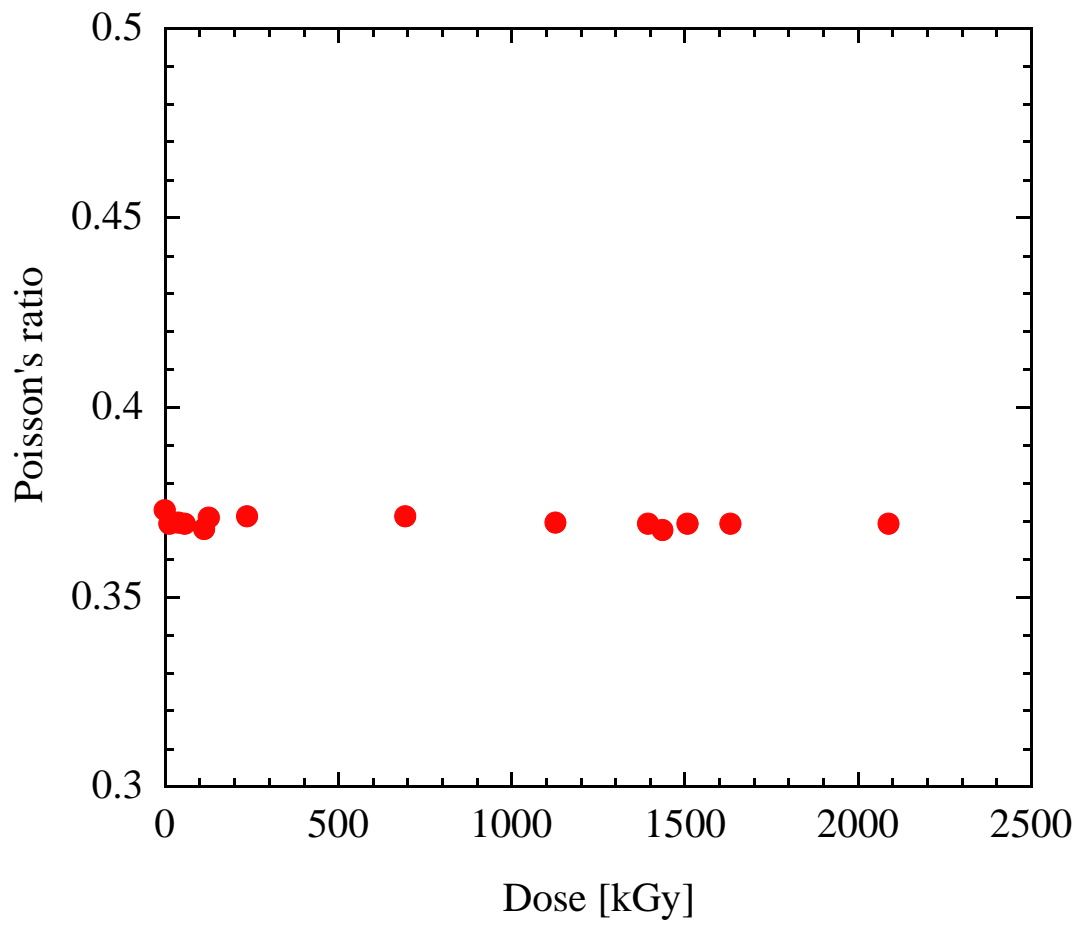

Figure 3. Poisson's ratio for various doses of gamma-ray up to $2090.24 \mathrm{kGy}$

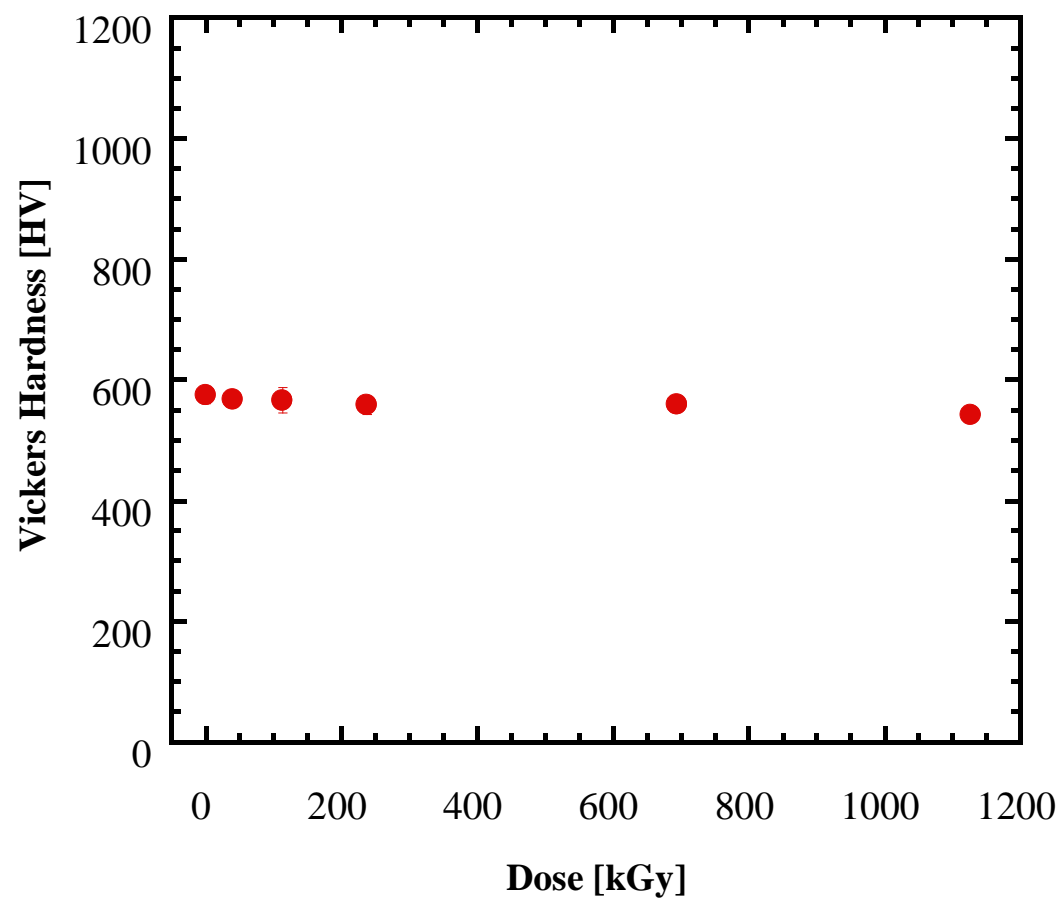

Figure 4. Vickers hardness for various gamma-ray doses up to $1127.5 \mathrm{kGy}$.

To investigate the change in the plastic deformation of the surface of samples caused by irradiation, Figure 4 shows the Vickers hardness result for various gammaray doses up to $1127.5 \mathrm{kGy}$. The graph shows a linear pattern of the Vickers hardness 
value, suggesting that gamma irradiation produces no effect on the sample surface's plastic deformation behavior, similar to the results reported by Higashi (2005). As a comparison, Figures 5 and 6 show the results of the indentation hardness, $\mathrm{H}_{\mathrm{IT}}$, and indentation modulus, $\mathrm{E}_{\mathrm{IT}}$, for various gamma-ray doses up to $694.38 \mathrm{kGy}$, respectively. The results show a slight increase in the values as the dose increases. Even so, huge error bars were observed. Since indentation tests investigate the plastic deformation of the near surface of the material, it is safe to conclude that the test only detected minor surface deformation. The indentation hardness $\mathrm{H}_{\mathrm{IT}}$ may be correlated to other hardness scales in certain circumstances. A common request is to express the indentation hardness as an equivalent Vickers hardness value (Fischer-Cripps, 2004). The indentation hardness uses the projected area of contact, while the Vickers hardness uses the actual surface area of contact. Since for a Vickers indenter the projected and actual surface areas of the contact differ by about $7 \%$, it is to be expected that the Vickers hardness value will be some $7 \%$ less than the equivalent indentation hardness, $\mathrm{H}_{\mathrm{IT}}$. Since the average Vickers hardness in this research has a slightly lesser value than its indentation hardness counterpart, it is therefore concluded that the values are in accordance with the statement above, and both results support each other. Minor changes in the indentation test and the Vickers hardness test, as well as the consistency in the elastic moduli and Poisson's ratio values as stated above, indicate that gamma-ray irradiation up to $2090.24 \mathrm{kGy}$ only caused minor defects on the samples' surface, and no significant changes in the bulk of the sample. Further research is needed to analyze the samples' surface deformation and morphology.

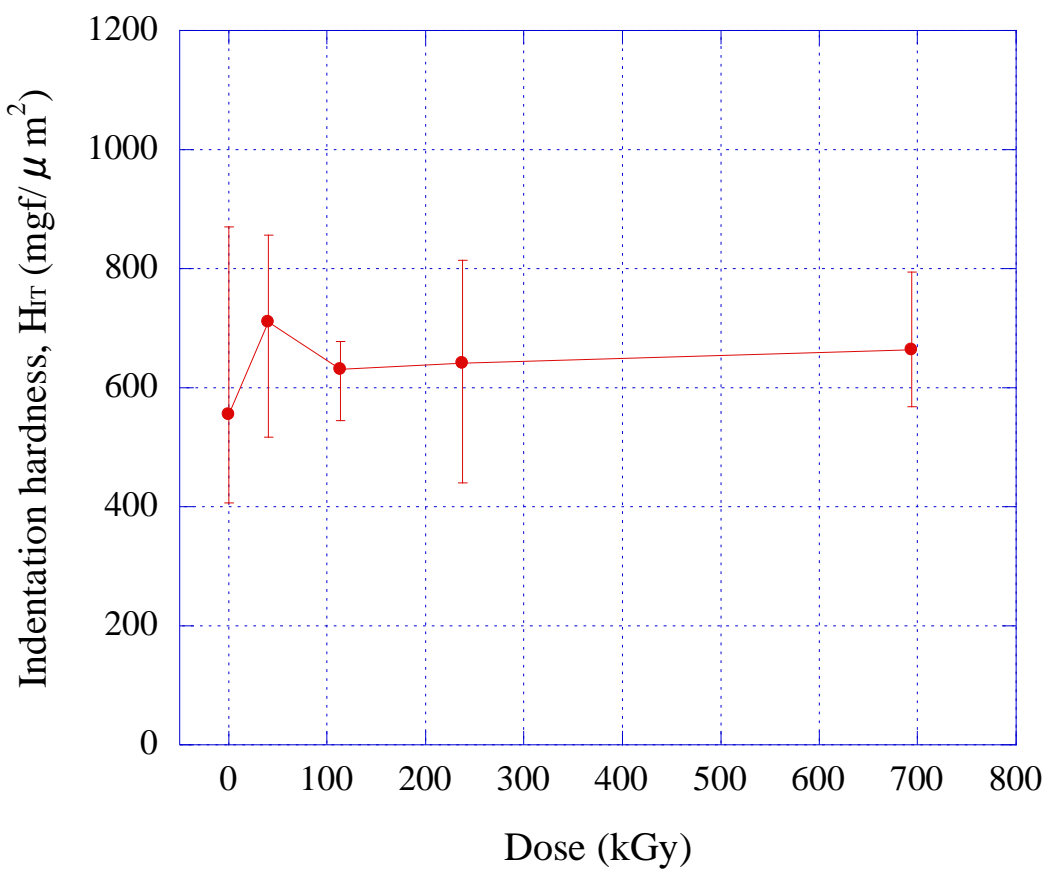

Figure 5. Indentation hardness, $\mathrm{H}_{\mathrm{IT}}$, for various gamma-ray doses up to $694.38 \mathrm{kGy}$. 


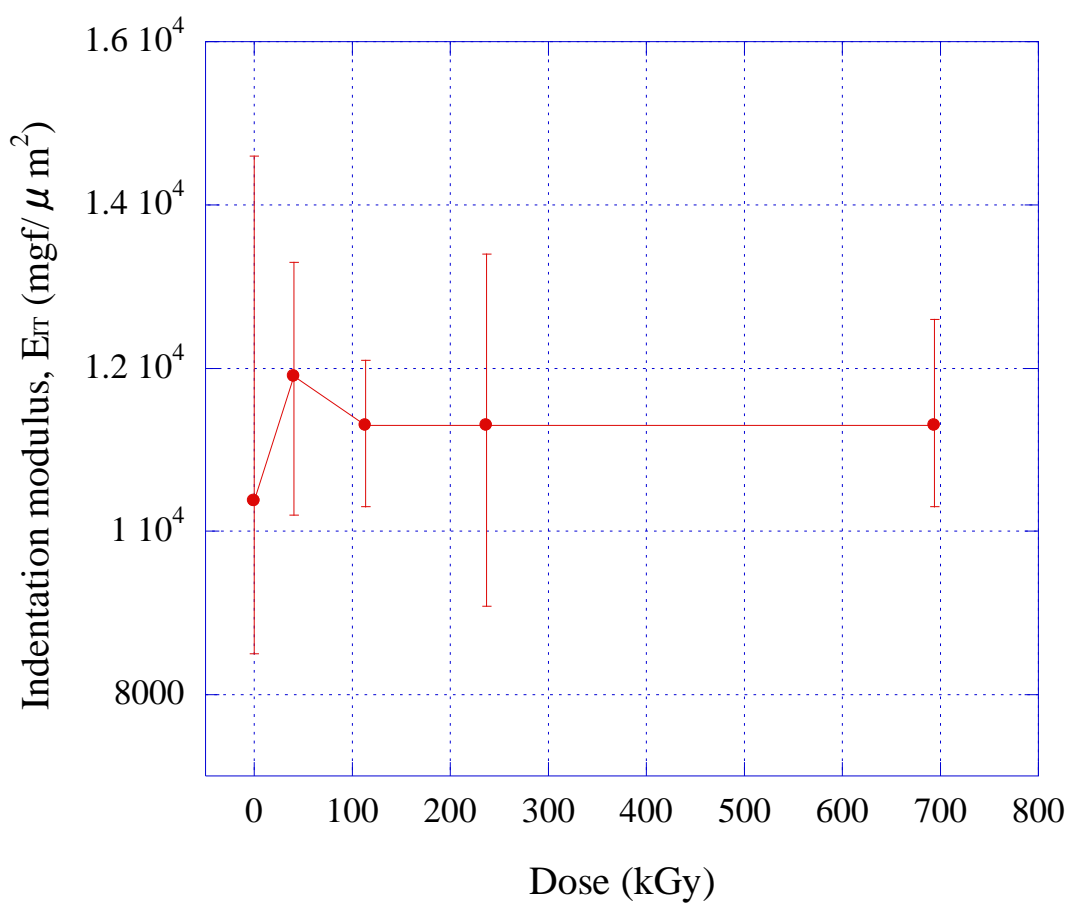

Figure 6. Indentation modulus, $\mathrm{E}_{\mathrm{IT}}$, for various gamma-ray doses up to $694.38 \mathrm{kGy}$.

Figure 7 shows the XRD spectrum of the samples up to a $1127.50 \mathrm{kGy}$ gamma-ray dose. It is clearly noted that all the samples show a broad halo peak, indicating an amorphous phase in the sample's atomic structure. From the XRD spectrum of Figure 7, it is evident that the background of the spectrum intensity tends to become slightly larger at higher values of $2 \theta$. This is a common phenomenon, and is due to the thermal vibration of the atom (Cullity, 1978). Not only does it reduce the intensity of the diffraction lines, but it also causes some general coherent scattering in all directions. This is called temperature diffuse scattering; it only contributes to the general background of the pattern, and its intensity gradually increases with an increase in $2 \theta$. In the energy range of $1.17 \mathrm{MeV}$ and $1.33 \mathrm{MeV}$ used in the sample preparation, the dominant process of gamma radiation interaction is the Compton effect, in which a phonon knocks an electron out of atomic orbit into a very much higher energy state. Atomic displacements can occur through internal bombardment by the Compton electrons, but very little damage is done. This is because electrons are relatively free to move and any ionization produced by radiation is soon neutralized by these electrons. The only net effect of gamma radiation on the metal is to generate a small amount of heat (Gedeon, 1993 ). The mechanical property results in this research also suggest that, similar to common metal behavior, nearly no change was observed in the BMG samples. Due to its mechanical stability, it is thus plausible to suggest that such BMG could be utilized as a structural material in gamma-ray rich environments, such as in nuclear reactors. Even so, further investigations, such as adding more doses of gammaray irradiation while investigating different aspects of the material, i.e. thermal and magnetic property, is vital before the definitive conclusion that $\mathrm{Zr}$-based BMGs can be used in structural applications can be made. 


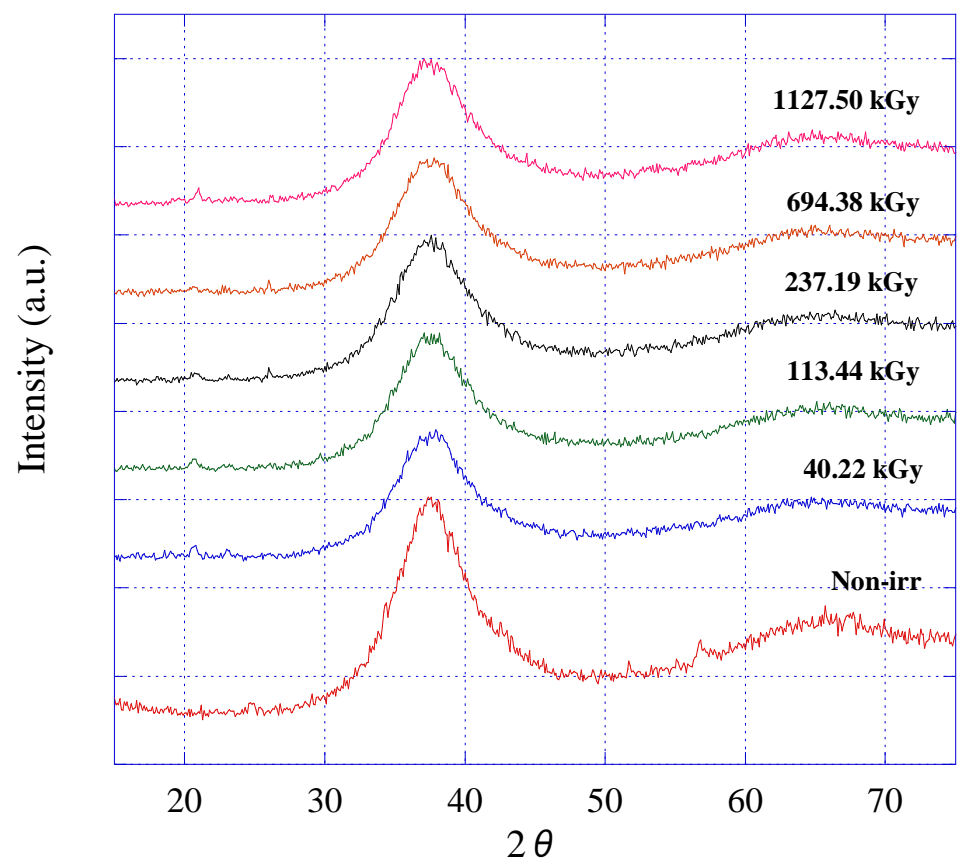

Figure 7. The XRD spectrum for various doses of gamma-ray up to $1127.50 \mathrm{kGy}$

\section{CONCLUSION}

The effects of gamma-ray irradiation on the mechanical properties of $\mathrm{Zr}_{55} \mathrm{Ni}_{5} \mathrm{Al}_{10} \mathrm{Cu}_{30}$ BMG were investigated using echometer measurements, Vickers hardness indentation tests and nanoindentation tests, as well as XRD analysis. The elastic modulus measurements, the Vickers hardness indentation tests and the nanoindentation tests indicate that the gamma ray irradiation (up to a dose of $2090.24 \mathrm{kGy}$ ) did not cause significant mechanical property changes in the bulk of the metallic glass. XRD spectra observed post irradiation confirms the amorphous behavior of the samples.

\section{ACKNOWLEDGEMENT}

The author would like to thank the technical staff of the Institute of Materials Research, Tohoku University for the provision of the bulk metallic glass, the Japan Atomic Energy Agency (JAEA) Takasaki Advanced Radiation Research Institute for conducting the gamma-ray irradiation process, and the Nagoya Institute for Fusion Science (NIFS), Nagoya, for the XRD experimentation. Financial support provided by the Malaysian Government through Universiti Malaysia Pahang is also gratefully acknowledged.

\section{REFERENCES}

Bruck, H.A., Christman, T., Rosakis, A.J. and Johnson, W.L. 1994. Quasi-static constitutive behavior of $\mathrm{Zr}_{41.25} \mathrm{Ti}_{13.75} \mathrm{Ni}_{10} \mathrm{Cu}_{12.5} \mathrm{Be}_{22.5}$. Scripta Metallurgica et Materialia, 30: 429-434.

Cullity, B.D. 1978. Elements of x-ray diffraction. 2nd ed. USA: Addison-Wesley Longman.

Dienes, G.J. and Vineyard, G.H. 1957. Radiation effects in solids. Vol. 2. New York: Interscience Publishers.

Fischer-Cripps, A.C. 2004. Nanoindentation. 2nd ed. New York: Springer. 
Gedeon, G. 1993. Nuclear plant material selection and application. New York:CED Engineering Handbook.

Gilbert, C.J., Ritchie, R.O. and Johnson, W.L. 1997. Fracture toughness and fatigue-crack propagation in a $\mathrm{Zr}$--Ti--Ni--Cu--Be bulk metallic glass. Applied Physics Letter, 71: 476-478.

Higashi, S. 2005. Ion and electron irradiation effect on Zr-based metallic glasses. Master Thesis, Tohoku University, Japan.

Inoue, A. 1995. High strength bulk amorphous alloys. Materials Transactions JIM, 36: 866-875.

Iqbal, M., Akhter, J.I., Hu, Z.Q., Zhang, H.F., Qayyum, A. and Sun, W.S. 2007. Mechanical properties and ion irradiation on bulk amorphous $\mathrm{Zr}_{55} \mathrm{Cu}_{30} \mathrm{Al}_{10} \mathrm{Ni}_{5}$. Journal of Non-Crystalline Solids, 353, 2452-2458.

Ishino, S. 1979. Irradiation damage. Japan:Tokyo University Press.

Johnson, W.L. 1999. Bulk glass-forming metallic alloys: science and technology. MRS Bulletin, 24, 42-56.

Kai, W., Hsieh, H.H., Nieh, T.G. and Kawamura, Y. 2002. Oxidation behavior of a Zr$\mathrm{Cu}-\mathrm{Al}-\mathrm{Ni}$ amorphous alloy in air at 300-425 $5^{\circ}$ Intermetallics, 10: 1265-1270.

Liu, L., Qiu, C.L., Sun, M., Chen, Q., Chan, K.C. and Pang, G.K.H. 2007. Improvements in the plasticity and biocompatibility of $\mathrm{Zr}-\mathrm{Cu}-\mathrm{Ni}$ - $\mathrm{Al}$ bulk metallic glass by the microalloying of $\mathrm{Nb}$. Materials Science and Engineering A, 449-451: 193-197.

Liu, L., Qiu, C.L., Zou, H. and Chan, K.C. 2005. The effect of the microalloying of Hf on the corrosion behavior of $\mathrm{ZrCuNiAl}$ bulk metallic glass. Journal of Alloys and Compounds, 399: 144-148.

Pang, S., Zhang, T., Kimura, H., Asami, K. and Inoue, A. 2000. Corrosion behavior of Zr-(Nb-)Al-Ni-Cu glassy alloys. Materials Transactions JIM, 41: 1490-1494.

Shah, L.H., Tsuchiya, B., Nagata, S. and Shikama, T. 2011. The effect of gamma-rays on the electrical properties of $\mathrm{Zr}_{55} \mathrm{Ni}_{5} \mathrm{Al}_{10} \mathrm{Cu}_{50}$ bulk metallic glass. Journal of Nuclear Materials, 417: 822-825.

Wang, J.G., Choi, B.W., Nieh, T.G. and Liu, C.T. 2000. Crystallization and nanoindentation behavior of a bulk $\mathrm{Zr}-\mathrm{Al}-\mathrm{Ti}-\mathrm{Cu}-\mathrm{Ni}$ amorphous alloy. Journal of Materials Research, 15: 913-922. 